\title{
FUNDAMENTOS CONCEITUAIS DA DEMONSTRAÇÃO DOS FLUXOS DE CAIXA: SIGNIFICADO, VANTAGENS E LIMITAÇÕES. ALGUMAS EVIDÊNCIAS.
}

\author{
Roberto Braga \\ Professor Doutor da FEA/USP \\ Pesquisador da FIPECAFI \\ José Augusto Veiga da Costa Marques \\ Professor da UFRJ \\ Doutor em Contabilidade e Finanças pela EAESP-FGV
}

\section{INTRODUÇÃO}

Nos recentes anos muito se tem comentado e discutido sobre a capacidade informativa dos relatórios financeiros, em especial a Demonstração das Origens e Aplicações de Recursos (DOAR; como ficou conhecida no Brasil após a emissão da Lei no. 6.404, de 1976) e a Demonstração do Fluxo de Caixa (DFC; a qual celebrizou-se com o pronunciamento no. 95/1987 do Financial Accounting Standards Board - FASB; órgão representativo da classe contábil nos Estados Unidos). Embora os dois demonstrativos apresentem dimensões, enfoques e bases próprias, ambos se propõem a informar sobre a liquidez e solvência do negócio - sua posição financeira - o que propicia o surgimento de dúvidas e equívocos a respeito de seus reais significados e composições.

Nesse sentido, este artigo possui por finalidade revitalizar um importante instrumento de avaliação financeira de empresas, a DFC, em busca de um melhor entendimento de seus fundamentos conceituais, assim como a exposição dos aspectos históricos envolvidos nas definições e limitações dos diversos fluxos contábeis disponíveis: Lucro, Capital de Giro Líquido e Caixa. Em adição, pretende-se mencionar algumas evidências que demonstram a relevância informativa do relatório.

\section{FLUXOS DE LUCRO E FLUXOS DE CAIXA}


As demonstrações de fluxo (Resultado; Mutações do Patrimônio Líquido; Origens e Aplicações de Capital Circulante Líquido e Fluxos de Caixa) e de estoque (Balanço Patrimonial) podem ser afetadas simultaneamente pela ocorrência das transações rotineiras.

MARTINS ${ }^{1}$ considera que o Balanço Patrimonial e a Demonstração de Resultado, se elaborados a luz do custo histórico puro e na ausência de inflação, representam a distribuição lógica e racional dos fluxos de caixa no decorrer do tempo.

Entende o autor que o ativo possui, além do disponível, direitos conversíveis em caixa em algum momento e bens que significam o montante do caixa desembolsado ou a desembolsar em razão de sua aquisição. Por sua vez, o Passivo constituiu-se de valores a desembolsar futuramente. Conclui, então, que o balanço inteiro possui ligação com o fluxo de caixa.

Admite também que a Demonstração de Resultado compõe-se de receitas que foram ou ser ao recebidas na forma de dinheiro e despesas que foram ou serão pagas do mesmo modo, o que condiciona que o lucro obrigatoriamente transita pelo caixa da empresa.

Em verdade, a diferença em termos de tempo entre o registro contábil da transação e sua efetiva realização financeira usualmente é pouco expressiva - exceção pode ocorrer no tocante às operações ligadas a contratos de longo prazo (setor imobiliário e produção por encomenda). $\mathrm{Na}$ realidade, a diferença consiste na distinção entre as duas bases de registro contábil existentes: regime de competência e regime de caixa, representados pela Demonstração de Resultado e pela DFC, que fornece, desse modo, relatórios e informações diferenciados.

SHILLINGLAW ${ }^{2}$ desenvolve uma abordagem semelhante ao caracterizar a fronteira entre as informações expressas por esses demonstrativos.

Para o autor, o desempenho operacional do negócio é medido usualmente pelo resultado contábil, com base na Contabilidade por regime de competência e na adoção de critérios apropriados de reconhecimento do lucro. Os resultados desse processo de mensuração são comunicados através da Demonstração de Resultado, que relaciona as receitas, despesas, ganhos e perdas da entidade. Contudo, o autor reconhece que a Demonstração de Resultado não divulga os efeitos de todos os eventos que afetam a liquidez da companhia - a capacidade em atender suas obrigações com caixa - nem reflete todos os fluxos de recursos dentro e fora da organização durante o período.

\footnotetext{
${ }^{1}$ MARTINS, Eliseu - Contabilidade vs. Fluxo de Caixa. Caderno de Estudos, São Paulo: FIPECAFI, abril, 1990.

${ }^{2}$ SHILLINGAW, G. \& MEYER, P.E. - Accounting: A Management Approach. Eught edition, Homewood, Illions: Irwin, 1986.
} 
Para superar essas dificuldades, a Demonstração das Mutações de Recursos (ou fundos) necessita ser elaborada. Nessa os recursos podem assumir a dimensão do caixa ou quaisquer outras formas de ativos líquidos ${ }^{3}$.

O mesmo autor esclarece as finalidades da Demonstração de Resultado e da demonstração de fundos que adota o conceito de capital de giro líquido (CGL). Expõe que a primeira sumariza a lucratividade econômica dos recursos disponíveis à companhia durante o período, ao passo que a segunda em contraste, mostraria como foram obtidos e utilizados esses recursos financeiros em igual período.

Explica que os relacionamentos entre a estrutura de recursos e os montantes aplicados como pagamento de dividendos, adições ao Ativo Permanente e transferências de dívidas de longo para curto prazo - significariam subsídios importantes à avaliação da gerência financeira e planejamento futuro pela administração. Além disso, menciona que esse relatório também forneceria indicativos sobre a capacidade do negócio para atender suas necessidades de curto prazo, por caixa.

Do mesmo modo, GOLUB e HUFFMAN ${ }^{4}$, adicionam às abordagens anteriores ao reconhecerem que, tradicionalmente, os usuários dos relatórios financeiros, na avaliação da capacidade do empreendimento em gerar fluxos de caixa futuros favoráveis, têm enfatizado informações sobre os lucros ao invés daquelas diretamente ligadas aos fluxos de caixa.

O primeiro tipo de informação, medida pela Contabilidade numa base em regime de competência, fornece uma indicação melhor do desempenho atual da companhia, que a informação em base de caixa. Todavia, ressaltam que a eficácia da mensuração do desempenho corrente de uma firma em estimar entradas líquidas de caixa futuras pode depender da qualidadecaixa de seu resultado, ou seja, a capacidade em converter seu fluxo de lucros em Fluxa de Caixa.

Do ponto de vista desses dois autores, ambos conjuntos de informações - Fluxos de Caixa e de lucros - são, de fato, relevantes. Os itens integrantes desses demonstrativos precisam ser analisados e interpretados ao longo de um período de anos, de modo a definirem tendências reveladoras. Consideram que tais avaliações expressam uma etapa crítica da estimação dos riscos associados ao investimento do negócio.

\footnotetext{
${ }^{3}$ Por exemplo, Capital Circulante Líquido e Ativos Monetários Líquidos.

${ }^{4}$ GOLUB, S.J. \& HUFFMAN, H.D. - Cash Flow: Why it Should be Stressed in Financial Reporting Financial Executive, v. 52 , n.2, february, 1984.
} 
Em estudo mais contundente, $|\mathrm{IJIR}|^{5}$ ressaltou as diferenças interpretativas entre as duas bases de registro contábil existentes, e procurou estabelecer um vínculo mais aceitável entre a avaliação de projetos de investimentos - quase sempre a partir de métodos que empregam fluxos de caixa - e da organização como um todo - por tradição e/ou simplicidade, a taxa de retorno contábil.

Uma vez que qualquer entidade significa, em essência, um conjunto de projetos de investimentos em agregado, não haveria fundamento em avaliá-la com base na taxa de retorno, ao passo que métodos extraídos de fluxos de caixa seriam utilizados para a análise de seus projetos individuais. Nesse aspecto, o autor elaborou um modelo algébrico com vistas a estabelecer uma estimativa da taxa de retorno das empresas, em função das taxas internas de retorno de seus projetos individuais, e também dos perfis de seus fluxos de caixa.

Por seu turno, KETZ e KOCHANEK ${ }^{6}$ enunciam a possibilidade de divergências entre os dois fluxos e daí a eventualidade de avaliações enganosas. Apontam que parte da explicação para a existência de diferentes registros contábeis alternativos aceitáveis tem sido a suposição da profissão contábil de que os relatórios financeiros com base na Contabilidade a regime de competência são mais significativas na medição do progresso econômico da firma do que são aqueles preparados numa base de caixa. Como decorrência, reconhecem que algumas organizações têm sido capazes de divulgar lucros impressionantes em suas demonstrações de resultado e, ainda assim, podem estar com necessidade de recursos financeiros para a manutenção de suas operações normais.

Já GUP e DUGAN ${ }^{7}$ privilegiam uma medida de caixa como melhor indicador da liquidez e solvência: o fluxo específico gerado das operações (cash flow from operations). Explicam que tal medida (CGO) começa com o capital de giro fornecido pelas operações, ao passo que as variações nas contas integrantes dos grupos circulantes associadas às operações (exceto disponibilidades) seriam acrescidas ou deduzidas daquele valor, daí resultando ${ }^{8}$ o CGO. Além

\footnotetext{
${ }^{5}$ IJIRI, Yuji. - Recovery Rate and Cash Flow Accounting. Financial Executive, v. 48, n. 3, march, 1980.

${ }^{6}$ KETZ, J.E. \& KOCHANEK, R.F. - Cash Flow: Assering a Company's Real Financial Executive, v.50, n.7, july, 1982.

${ }^{7}$ GUP, B.E. \& DUGAN, M. T. - The Cash Flow Statement: The Tip of na Iceberg. Business Horizons, v.31, n.6, november/december, 1988.

${ }^{8} \mathrm{Na}$ realidade, este procedimento consiste numa aproximação ao montante efetivo do caixa gerado das operações, o qual é mais facilmente obtido pela diferença líquida entre os recebimentos e pagamentos de natureza opcional.
} 
disso, ressaltam sobre a existência de outras medidas semelhantes de fluxos de caixa conseguidas por meio de modificações nos itens de ajustamento aos lucros. Por exemplo, o efeito de ganhos ou perdas oriundos de alienações ou baixas de ativos fixos, de investimentos registrados pelo método de equivalência patrimonial, na amortização de prêmios e deságios de debêntures e de outras transações que poderiam ser removidas.

Os diversos pontos de vista citados convergem no sentido de que a Demonstração de Resultado visa relatar o desempenho da lucratividade, uma medida mais voltada ao médio e longo prazo.

Entretanto, permanece obscuro qual relatório revelaria o desempenho da liquidez e solvência de modo mais adequado, se o de fluxos de capital de giro líquido (CGL) ou o de caixa. Enquanto MARTINS, SHILLINGLAW, e GOLUB e HUFFMAN estão mais preocupados em distinguir os dois conjuntos de informações, IJIRI prende-se a críticas ao resultado contábil e GUP e DUGAN realçam um indicador ideal para a liquidez; KETZ e KOCHANEK discutem as implicações na análise de fluxos divergentes.

\section{FLUXOS DE CAPITAL DE GIRO LÍQUIDO E FLUXOS DE CAIXA}

O conceito de Capital Circulante Líquido, mais conhecido em Finanças por CGL, possui seu montante discriminado na DOAR pela diferença entre os totais das origens e aplicações de recursos, e também através da variação entre a diferença dos grupos circulantes no exercício corrente - Ativo Circulante (capital de giro) menos Passivo Circulante - e aquela verificada no período imediatamente anterior.

Outros conceitos de recursos poderiam ser adotados na demonstração como, por exemplo, ativos monetários líquidos, caixa e equivalentes ou caixa; cada qual sinaliza uma dimensão da liquidez da empresa. Todavia, o conceito requerido pela Lei no. 60404/76 - Capital Circulante Líquido - tem sofrido críticas nos últimos anos, sobretudo aquelas dirigidas a sua fundamentação teórica: a classificação de Ativos e Passivos em circulante e não circulante.

No início dos anos 60, alguns trabalhos enfatizavam a importância do conceito de CGL como indicador da liquidez das entidades. Em seu estudo, MAURIELLO ${ }^{9}$, considerou esse conceito importante para a administração como uma medida de liquidez do capital e como um indicador, no

\footnotetext{
${ }^{9}$ MAURIELLO, L.A. - The Working Capital Concept: A Resatement. The Accounting Review, v.37, n.1, january, 1962.
} 
balanço, da estrutura entre o Ativo e o Passivo da companhia. Em seu entender, bancos e outros credores de curto prazo estariam bastante interessados no montante do CGL sob a perspectiva de recebimento de seus créditos contra a firma.

Sob esse prisma, pode-se perceber uma posição até certo ponto estática e limitada do autor na percepção do significado do conceito.

A um passo adiante, $\mathrm{FESS}^{10}$ reconheceu que, há poucas décadas atrás, o conceito era visto como uma medida de endividamento ou habilidade da empresa em honrar suas obrigações em casos de liquidação. Comenta, entretanto, que o enfoque passou nestes últimos anos da questão da liquidação para a do ciclo operacional, o qual enfatiza a habilidade do negócio em cumprir seus compromissos vencíveis a curto prazo com os recursos gerados pelas operações correntes.

Com base nessa abordagem o autor apontou duas dimensões para a análise financeira do CGL: (1) a apresentação do montante do CGL em um dado momento para indicar uma medida bruta da margem ou proteção disponível para cumprir obrigações de curto prazo (análise estática); e (2) o relato do fluxo de CGL para períodos passados e o fluxo esperado para períodos futuros (análise dinâmica).

Não obstante, FESS $^{11}$ considerou a definição de ciclo operacional defendida pelo AICPA - através do Accounting Research Bulletin no. 43 - como um obstáculo ao pleno entendimento do conceito e, por extensão distorcida das suas dimensões de análise financeira de liquidez e à realização de ativos. Para FESS, o Ativo Circulante pode incluir que tenham sido mantidos por $\operatorname{anos}^{12}$, como o caso das destilarias, e também Estoques que giram muitas vezes ao ano, como nas empresas varejistas. Os usuários poderiam utilizar, portanto, diferentes conjuntos de padrões para orientá-los em suas análises do CGL sobre segmentos distintos.

Numa segunda questão, explica que existe alguma inconsistência na inclusão dos seguros pagos antecipadamente com validade de três anos no Ativo Circulante ${ }^{13}$, por exemplo, enquanto máquinas e equipamentos com vida útil equivalente seriam excluídos.

\footnotetext{
${ }^{10}$ FESS, P.F. - The Working Capital Concept. The Accounting Review, 4.45, n.2, april, 1966.

${ }_{11}^{11}$ FESS, P.F. - Op..cit.

${ }^{12}$ Em conformidade `a correta técnica contábil, esses Estoques deveriam ser mostrados em conta do Ativo Realizável a Longo Prazo e, se considerados obsoletos, seu valor contabilizado baixado como perda do exercício.

${ }^{13}$ De acordo com os dispositivos legais em vigor no País, a parcela dos seguros antecipados, cuja cobertura excedesse ao término do exercício seguinte deveria ser classificada no Ativo Realizável a Longo Prazo. As normas norte-americanas requerem a divulgação em detalhe dos prazos em notas explicativas.
} 
Além dos dois aspectos acima, o autor cita um terceiro problema, relativo à diversidade de métodos para avaliação do Ativo Circulante. Em vista de tais dificuldades, a análise do CGL ficaria comprometida.

A fim de contornar as dificuldades em classificar Ativos e Passivos em circulante ou não, FESS $^{14}$ sugeriu uma nova classificação das contas do balanço de modo a enfatizar a maneira pela qual os recursos seriam empregues pela companhia. Em outras palavras, o autor defendia uma maior exposição da vinculação entre origens de recursos (capitais de terceiros e próprio) e suas destinações (ativos). Entretanto, sua proposta não logrou respaldo dos contadores e analistas financeiros da época.

Em estudo mais polêmico, HEATH ${ }^{15}$ criticou a base de sustentação do conceito - a classificação de Ativos e Passivos em circulante e não circulante considerando-a uma prática enganosa que deveria ser abandonada, de certo modo aprimorando abordagem de FESS. Segundo HEATH, esses termos não possuem um significado verdadeiro independente das propostas a serem servidas em suas definições. Esses termos podem ser definidos em Contabilidade e Finanças de muitas maneiras diferentes. Esclarece que a procura das definições verdadeiras de Ativo Circulante, Passivo Circulante e CGL poderiam apenas resultar em confusão e, por último, em fracasso.

O autor identifica como principal objetivo dessa classificação (dos elementos do balanço) fornecer informações úteis para avaliação da solvência da entidade, mas contesta sua conceituação. HEATH refutou os três argumentos que sustentam a formulação da classificação: (1) como um meio de evidenciar importantes atributos de ativos e passivos; (2) como um instrumento de previsão e falência; e (3) como uma conveniência aos usuários para o cálculo de índices.

Quanto ao primeiro argumento, o autor assume que a classificação atual do balanço Patrimonial tem sido descrita na literatura contábil como inconsistente, ilógica e irracional. Um motivo reside no fato de itens classificados no circulante não possuírem atributos significativos em comum. Entende que não existe um atributo identificável ao qual todos os Ativos classificados no Circulante possuam, que os não circulantes não tenham.

Cita, então, alguns exemplos clássicos que reforçam seu ponto de vista, tais como a inconsistência em classificar prêmios de seguros com cobertura de três anos como circulante, enquanto uma máquina com vida útil semelhante seria classificada como não circulante; classificar estoques de óleo cru em tanques como circulante ao passo que o similar em reservas

\footnotetext{
${ }^{14}$ FESS, P.F. - Op.cit.

${ }^{15}$ HEATH, Loyd C. - Is Working Capital Really Working? Journal of Accountancy, v.150,n.2, august, 1980.
} 
subterrâneas seria classificado como não circulante; e a prática em classificar como circulante materiais e peças de reposição que serão usadas nas operações, enquanto os similares seriam classificados como não circulante ${ }^{16}$.

O critério de realização do Ativo Circulante, durante o ciclo operacional, ficaria, deste modo, sob suspeição.

No tocante à segunda questão - classificar Ativos e Passivos em circulante ou não circulante de forma a servir de instrumento na predição de falência - o autor considerou o conceito de CGL um indicador limitado para aquele fim; apoiou-se em pesquisas que concluíram que índices fundamentados nessa classificação são provisões medíocres da falência financeira. Resumiu, que nenhum deles previu a falência de modo seguro, em quaisquer dos cinco anos anteriores, como o quociente Fluxo de Caixa / Exigível Total.

O autor também alertou que a utilização dessa classificação para servir de conveniência aos usuários no cálculo de índices também constituiu-se num argumento tendencioso, haja vista a possibilidade de decisões enganosas obtidas da exclusiva avaliação de algumas medidas dela extraídas.

Com o intuito de minorar as distorções existentes, HEATH propôs três recomendações. A primeira constituiu-se no relato de informações suplementares sobre atributos de Ativos e Passivos específicos. Explica que informações sobre o montante e o prazo dos recebimentos e pagamentos de caixa das contas a receber e obrigações deveriam ser expostas adicionalmente em notas explicativas a fim de auxiliar o usuário na previsão do fluxo de caixa do negócio. O prazo de vencimento dos valores a recebe, por exemplo, poderia prognosticar a redução das receitas de caixa no período seguinte.

O autor sugeriu ainda a classificação do Passivo Exigível com base nos diferentes tipos de fonte de crédito disponíveis para as empresas. Duas fontes foram identificadas. Fontes espontâneas, que crescem dentro dos padrões normais das operações econômicas realizadas, sem um esforço especial ou decisão consciente por parte da administração e tendem a ser diretamente proporcional às vendas, enquanto as fontes negociadas - o outro tipo - dependeriam mais da avaliação de credores sobre a situação da organização.

\footnotetext{
${ }^{16}$ Grande parte desses problemas não ocorre no Brasil em razão da presença de critérios diferenciados para evidenciação. Nos EUA as normas solicitam o relato do Ativo em suas partes correntes (circulante) e fixa, ao passo que no Brasil nos grupos Circulante, Realizável a longo prazo e permanente.
} 
HEATH listou como fontes espontâneas os créditos decorrentes da atividade operacional: (a) operacionais (por exemplo, salários e encargos sociais a pagar); e o (b) fiscais (como impostos sobre valor agregado a recolher). Já as fontes negociadas remetem à natureza financeira (empréstimos e financiamentos bancários). Essa classificação alternativa aumentaria o caráter informativo do Passivo Exigível.

A terceira sugestão diz respeito à manutenção da atual ordenação de liquidez mostrada para os Ativos no balanço convencional, mas sem a menção dos termos circulantes e não circulantes (os grupos de contas patrimoniais de longo prazo). Para HEATH, uma reformulação nessa estrutura poderia causar maior confusão aos usuários, acostumados àquela forma de evidenciação.

Em suma, HEATH criticou o conceito de CGL diretamente em sua base, três fundamentos teóricos que sustentam a classificação. Abalado o suporte estrutural do conceito, o autor sugeriu três medidas que supostamente elevariam o caráter informativo do balanço patrimonial.

De 1980 até o momento atual surgiram estudos recomendando o uso da DFC em substituição ao relatório que empregava o conceito de CGL. Os trabalhos de HEATH e ROSENFIELD ${ }^{17}$, HOPP e LEITE ${ }^{18}$, e HENDRISKEN e BALDA ${ }^{19}$, dentre outros, parecem seguir essa linha. Nesse sentido, os autores apresentam muitos pontos em comum no que concerne à argumentação em defesa da demonstração dos recebimentos e pagamentos de caixa (DFC) como um sinalizador melhor da liquidez, solvência e flexibilidade financeira das empresas. Tal argumentação foi construída com base na exposição de inúmeras críticas ao conceito de CGL e, novamente, à usual classificação de Ativos e Passivos em circulante e não circulante.

HEATH e ROSENFIELD partem de um estudo evolutivo da avaliação da solvência antes como um objetivo básico de credores na medição da capacidade de pagamento de dívidas das entidades - ressaltando a mudança do enfoque de uma análise estática do CGL para outra dinâmica com base no fluxo de caixa, semelhante à abordagem de FESS.

Salientam que solvência e lucratividade seriam obtidas a partir do Fluxo de Caixa e da Demonstração de Resultado, respectivamente; existindo uma relação entre esses conceitos no longo prazo, muito embora possam não andarem juntos em curtos períodos de tempo. Conforme

\footnotetext{
${ }^{17}$ HEATH, L.C. \& ROSENFIELD, T. - Solvency: The Forgotten Half of Financial Reporting. Journal of Accountancy, v. 146, n.4, october, 1978.

${ }^{18}$ HOPP, J.C. e LEITE, H.P. - O Mito da Liquidez. Revista de Administração de Empresas, São Paulo: FGV, v.29, n.4, out/dez, 1989.

${ }^{19}$ HENDRISKEN, E.S. \& VON BALDA, M. F. - Accounting Theory. Fifth edition, Homewood, Illinois: Irwin, 1993.
} 
tais autores, qualquer informação que forneça sinais sobre o montante, o prazo e a certeza dos futuros recebimentos e pagamentos de caixa do empreendimento seria útil na avaliação da solvência.

Em princípio, a dimensão temporal é que dita as diferenças existentes entre a solvência (cash basis accounting) e a lucratividade (accrual accounting basis). Esse posicionamento igualase aos de MRTINS e SHILLINGLAW, já mencionados.

HEATH e ROSENFIELD enumeram uma lista de evidências que comprovariam a "negligência" dos contadores com respeito à solvência:

1. a enganosa forma de classificação do Balanço - inicialmente voltada para interesses dos credores desde há muitas décadas e, para os propósitos atuais, inadequadas;

2. o mau direcionamento da demonstração de fundos - que adotou por longo tempo o conceito de CGL (antes considerado útil), mas hoje substituído pela dos Fluxos de Caixa ( o SFAS no. $95 .^{20}$ em vigor nos Estados Unidos);

3. a rejeição das exigências dos usuários - fato motivado pelo FASB considerar o lucro como um melhor indicador da geração futura de caixa das empresas. Esse comportamento mudou com a emissão do SFAS no. 95. Na realidade, a figura do lucro e do caixa se complementa, ambos representam diferentes coisas para diferentes propósitos;

4. a confusão associada aos efeitos sobre o lucro operacional e o caixa gerado das operações - sobretudo por mostrar o lucro líquido como uma origem de CGL seguida de um conjunto de mais e menos;

5. os efeitos da inflação sobre a solvência, que deveriam ser reconhecidos nas demonstrações por meio de ajustes ao nível geral de preços ou mediante a adoção do custo de reposição, o que proporcionaria uma informação mais relevante na previsão de futuros recebimentos de caixa;

6. as entidades econômicas e legais - referem-se aos demonstrativos consolidados e à possibilidade destes esconderem problemas de insolvência de uma ou outra subsidiária no fluxo de caixa consolidado. Os autores recomendam a publicação individualizada de tais relatórios; e as informações sobre obrigações de fundo de pensão ${ }^{21}$ - sugerem seu registro

\footnotetext{
${ }^{20}$ Statement of Financial Accounting Standars no. 95 - Statement of Cash Flows. Financial Accounting Series. Financial Accounting Standards Board of the Financial Accounting Foundation, november, 1987.

${ }^{21}$ Os autores referem-se à contribuição das transações que envolvem contribuições e pagamentos de benefícios previdenciários das empresas norte-americanas.
} 
contábil no balanço, embora os órgãos normativos norte-americanos não o tenham exigido até então.

HEATH e ROSENFIELD fazem ainda uma alusão aos contadores pelo "esquecimento do ponto de vista da solvência" e recomendam a substituição, 'a época, da demonstração de fundos pela de fluxos de caixa.

Por sua vez, HOPP e LEITE criticam a utilização de índices financeiros como instrumento de avaliação da liquidez das empresas, em especial por representarem uma medição estática que pressupõe a liquidação imediata da entidade, sem considerar a continuidade de suas operações. Entendem que o negócio vale pelo que suas operações podem produzir de rendas no futuro e, assim, somente em caso de liquidação o patrimônio líquido, apreços de mercado, teria alguma utilidade para o avaliador.

Esses autores questionam também a supervalorização dos índices pelas seguintes razões: seriam inconsistentes (por exemplo, o pagamento de uma dívida aumenta a liquidez); há arbitrariedade no estabelecimento de padrões ideais ${ }^{22}$, o aspecto de estarem estruturados com base no balanço, o qual Ihes transferiria problemas de avaliação, mensuração e classificação de ativos e passivos.

A classificação usual mostrada no Balanço Patrimonial foi, outra vez questionada. Seguindo a linha de argumentação de HEATH, os autores enfatizaram a classificação do Passivo conforme suas fontes - espontâneas ou contratadas - e sugeriram seu abandono, o que conduziria a uma suposta maior relevância informativa na avaliação da solvência.

A capacidade preditiva de falência daqueles quocientes foi também criticada, com ênfase na pesquisa clássica realizada por $\operatorname{BEAVER}^{23}$, que concluiu serem os índices de fluxos de caixa sobre dívidas melhores previsores que os estruturados sobre a classificação circulante/não circulante.

HOPP e LEITE atentam para a possibilidade enganosa de se considerar quocientes mais elevados como necessariamente desejáveis, verificaram que, à despeito da crise da época, os indicadores financeiros mostravam-se crescentes ‘a custa do sucateamento do imobilizado (as despesas de depreciação superavam os investimentos realizados permanente), situação esta em

\footnotetext{
22 Entende-se por "padrões ideais" aqueles valores usados como referência pelas empresas do setor os quais, se mantidos, viabilizaram, em princípio, a continuidade de suas operações rotineiras ad perpetum.

${ }^{23}$ BEAVER, W.H. - Alternative Accounting Measures as Predictors of Failure. The Accounting Review, v.43, n.1, january, 1968.
} 
que a firma torna-se incapaz de remunerar seus acionistas mais do que aquela proporcionada pelo mercado financeiro.

Do mesmo modo que HEATH e ROSENFIELD, estes últimos também consideram a análise dinâmica da DFC como uma medida melhor da liquidez mas adiciona a esta a importância de informações não contábeis `a avaliação.

Por seu turno, HENDRISKEN e BALDA retornam às mesmas questões e sistematizam as opiniões correntes, inclusive aquelas que sugerem a quebra da demonstração que divulga as variações do CGL, ou sua substituição pela DFC. Mencionam a existência de sugestões no sentido de que o balanço Patrimonial seja classificado sob a base do método de avaliação e citam como alternativas a classificação dos passivos com base no tipo de fonte credora disponível à firma e, ainda, a exposição de informações suplementares, no tocante ao montante e prazo dos recebimentos e desembolsos de caixa ligados a ativos e obrigações específicos.

Explicam que os Passivos poderiam ser distribuídos entre fontes espontâneas e negociadas, isto é, como originadas das operações normais da firma - como créditos comerciais usuais e provisões - ou de negociações específicas da organização com bancos ou outras instituições financeiras emprestadoras para financiamentos de curtos ou longos prazos. Essa classificação seria relevante, haja vista as primeiras fontes seriam automáticas, ao passo que as últimas demandaram negociações e a avaliação do emprestador sobre a posição financeira do solicitante. Quanto à outra alternativa, defendem a inclusão de quadros relacionando contas a receber e a pagar pelas datas devidas e tabelas mostrando o montante e prazo dos juros, arrendamentos financeiros e demais recebimentos e desembolsos periódicos associados a contratos de financiamento.

Citam ainda o estudo clássico de $\operatorname{VATTER}^{24}$, que recomendou a elaboração de demonstrativos especiais para exposição do estado de liquidez da companhia. Estas deveriam divulgar as fontes de caixa na liquidação e as restrições especiais com relação ao uso de ativos ou origens de caixa particulares. No balanço convencional, a paridade dos Ativos aos Passivos circulantes conduz à falsa suposição que, na liquidação os credores de curto prazo necessariamente possuem alguma prioridade sobre os Ativos registrados e que somente 0 excesso ficaria disponível aos credores de longo prazo. Um demonstrativo de solvência deveria

\footnotetext{
${ }^{24}$ VATTER, W.H. - The Fund Theory of Accounting and the Implications for Financial Reports. Chicago: University of Chicago Press, 1947.
} 
mostrar as prioridades específicas que existam e os direitos de todos os credores gerais, independente da natureza de curto ou longo prazo.

Parece bastante evidente que as recomendações de HEATH foram acolhidas pelos diversos autores. Estes construíram suas argumentações a favor de um instrumento presumivelmente mais adequado para avaliação da liquidez e solvência: o Demonstrativo de Fluxos de Caixa, instrumento que deveria substituir a demonstração de fundos convencional. Por outro lado, as deficiências desse outro conceito não foram exploradas pelos autores citados. Por exemplo, o caixa consumido pelas operações não significa, necessariamente, que a entidade esteja em processo de insolvência. O estágio de vida da empresa também deveria ser considerado nessa avaliação.

Dessa maneira, admitindo-se o conceito de caixa e equivalentes como medida mais confiável para sinalização da liquidez e solvência do negócio, a percepção de suas limitações e a verificação de sua relevância informativa tornam-se aspectos pertinentes.

\section{DEFICIÊNCIA E PROBLEMAS DA DFC}

Algumas das vantagens mais enfatizadas da Demonstração dos Fluxos de Caixa podem ser agrupadas nas seguintes classes:

1. encontra-se isenta dos procedimentos de rateio arbitrários usuais;

2. focaliza a atenção do leitor ao valor "verdadeiro" (em sinônimo a objetivo) do dinheiro, considerado como a medida mais apropriada para mensurar a empresa em continuidade;

3. possibilita à administração projetar o futuro da organização;

4. a maior confiabilidade do investidor relativa ao índice preço por ação/ fluxo de caixa descontado por ação - em comparação ao P/L convencional - permite decisões de investimento mais acertadas;

5. proporciona melhor visualização da capacidade de pagamento dos investimentos realizados e da política financeira empregue; e

6. fornece uma melhor avaliação da qualidade de gerência financeira do negócio.

Não obstante, à despeito das alegadas vantagens motivadas pela suposta ausência de procedimentos arbitrários de apropriação, a DFC tem sofrido críticas inerentes a seu formato 
sugerido. GUP e DUGAN ${ }^{25}$ relacionaram algumas delas identificadas em outros estudos: HEATH ${ }^{26}$ argumenta que o FASB retalhou e passou superficialmente ao transformar a Demonstração das Mutações na Posição Financeira da DFC. Afirma que o relato das atividades operacionais, e das atividades Não caixa de financiamento e investimento, está ainda confuso. DRTINA e LARGAY ${ }^{27}$ reivindicaram que o método indireto de apresentação pode não fornecer o Fluxo de Caixa das operações devido a problemas conceituais e práticos. $\mathrm{KOCHANEK}^{28} 28$ argumenta que o capital de giro das operações não representa o mesmo e nem move-se necessariamente na mesma direção que o Fluxo de Caixa das operações ${ }^{29}$.

Os autores enfatizaram que, como instrumento de decisão, o relatório por vezes poderia ser confuso e potencialmente enganoso. Citam, por exemplo, que um Fluxo de Caixa operacional negativo (consumo de caixa pelas operações) poderia constituir um indicador favorável de capacidade econômica caso a firma estivesse crescendo rapidamente, ou mesmo a uma taxa moderada, ao passo que esse fluxo positivo (geração de caixa pelas atividades operacionais) poderia representar um sinal de desastre eminente.

Mencionaram ainda o caso clássico da W.T. Grant, no qual aquele fluxo foi positivo no ano anterior `a falência, graças à liquidação emergencial de seus estoques. Esses autores também ressaltaram que os fluxos de caixa podem flutuar entre montantes positivos e negativos para empreendimentos sazonais.

Percebe-se a partir dessas constatações que fluxos de caixa positivos não significam necessariamente uma situação favorável, enquanto montantes negativos podem em muitas ocasiões não espelhar uma situação desfavorável.

Em adição, essa argumentação parece sinalizar que a DFC, tomada de maneira isolada, poderia fornecer informações inverídicas e, assim, reforçar os pontos de vista que defendem seu caráter complementar - mas nunca substitutivo - às informações dispostas nos relatórios convencionais erguidos com base no regime de competência, em especial na Demonstração de Resultado.

\footnotetext{
${ }^{25}$ GUP, B.E. \& DUGAN, M.T. - Op. Cit.

${ }^{26}$ HEATH, L.C. - Cash Flow Reporting: Bankers Need a Direct Approach. The Journal of Commercial Bank Lending, february, 1987.

${ }_{27}^{27}$ DRTINA, R. \& LARGAY, J.A. - Pitfalls in Calculating Cash Flow form Operations. The Accounting Review, v.60, n.2, april, 1985.

${ }^{28}$ KOCHANEK, R. - Funds Statement. Financial Executive, v.3, n.1, january, 1987.

${ }^{29}$ GUP, B.E. \& DUGAN, M.T. - Op.cit., p. 49-50.
} 
Por sua vez, o estudo de MAHONEY, SEVER e THEIS ${ }^{30}$, apontou problemas com a implementação de determinadas regras solicitadas pelo SFAS no. 95, principalmente para instituições financeiras e aquelas empresas com significativas transações no exterior. Acreditam que para muitas companhias a adoção das novas regras seria tranqüila, fato comprovado por uma recente pesquisa da Fortune 500, a qual revelou que cerca de $50 \%$ vinham classificando as transações de acordo com as atividades: operacional, de financiamento e de investimento.

Os autores reconheceram, entretanto, que instituições financeiras e companhias com operações no exterior, poderiam encontrar dificuldades na implementação da Instrução.

Entendem que uma questão primordial para muitos bancos consiste na apresentação de fluxos de caixa brutos, uma vez que habitualmente o setor pública as variações líquidas em títulos de investimento, empréstimos e certificados de depósito, ao invés de recebimentos e pagamentos brutos de caixa ${ }^{31}$.

Aliado a esse fato, a maior parte das companhias com operações no exterior teriam de evidenciar os efeitos de mudanças nas taxas de câmbio, diferentemente da prática passada.

Nesse sentido, acham que os elaboradores da DFC desses dois grupos de empresas deveriam verificar se a informação necessária estaria disponível e, em caso contrário, quais ações precisariam ser empregues de modo que sua implementação segundo as novas normas pudesse ser realizada.

Esses autores explicaram que o SFAS solicitou que as companhias registrem o equivalente de fluxos de caixa em moeda estrangeira com base nas taxas de câmbio sobre o caixa fosse divulgado como um item separado na demonstração. Em vista disso, os autores recomendaram uma abordagem de consolidação em três passos que, embora envolvesse procedimentos padrões, não vinha sendo seguida por grande número de firmas na publicação do relatório proposto no APB OPINION no. 19:

1. preparar DFCs separadas na moeda local de cada operação;

2. traduzi-las para moeda corrente de evidenciaçao; e

3. consolidar as demonstrações separadas.

\footnotetext{
${ }^{30}$ MAHONEY, Jonh J. \& SEVER, Mark V. \& THEIS, Jonh .A. - Cash Flow: FASB Opens the Floodgates. Journal of Accountancy, v. 165, n.5, may, 1988.

${ }_{31}$ Em 1990, o FASB emitiu o SFAS n. 104, permitindo, às companhias do setor financeiro, a divulgação em valores líquidos.
} 
NASSER $^{32}$, por sua vez, relacionou alguns estudos críticos sobre a DFC e ressaltou o desenvolvido por RUTHERFORD ${ }^{33}$, que reconheceu que a contabilidade de fluxos de caixa não se encontra isenta de rateios e, portanto, contém muitos problemas de julgamento similares em natureza e impacto àqueles associados ao sistema usual. $\mathrm{O}$ autor mencionado conceituou como maquilagem (window dressing) o reflexo causado pelo corte, antecipação ou atraso consciente dos recebimentos e pagamentos de caixa, e considerou que a natureza do relatório poderia criar variabilidades nos fluxos de caixa, que necessitariam ser camufladas numa tentativa de melhorálos num exercício específico, ou as tendências dos resultados financeiros num período mais longo.

Os procedimentos envolvidos causariam efeitos no curto prazo em muitos casos, ao passo que um período contábil seria beneficiado à custa de outros. Em suma, RUTHERFORD reconheceu a suscetibilidade da DFC às manipulações de curto prazo. Essa também parece ser a posição de MARTINS ${ }^{34}$ e IUDíCIBUS ${ }^{35}$.

O estudo realizado por MAKSY ${ }^{36}$ parece respaldar a posição de DRTINA e LARGAY citada. O autor identificou duas discrepâncias - Tipos I e II - surgidas quando as variações nos itens circulantes operacionais (exceto o Caixa) mostradas na DFC e as alterações derivadas de Balanços Patrimoniais sucessivos não coincidem.

Para MAKSY, as discrepâncias do Tipo I ocorrem quando as mudanças nas contas individuais de CGL divulgadas na DFC não se igualam às alterações nessas mesmas contas quando não derivadas de balanços comparativos. Por exemplo, a demonstração poderia exibir uma elevação de $\$ 50.000$ em estoques, enquanto os balanços indicariam um aumento de $\$$ 70.000. Nesse caso, a variação no fluxo total, se igualaria àquela do fluxo total obtida dos balanços.

Já a discrepância do Tipo II surge quando a modificação no fluxo total relatada na DFC não se iguala à alteração naquele derivado dos balanços comparativos. Ressalta o autor que aqueles demonstrativos que contenham discrepâncias do Tipo II normalmente também incluem uma ou mais do Tipo I expressivas.

Com base num conjunto de empresas analisadas, o autor identificou quatro causas principais de discrepâncias:

\footnotetext{
${ }^{32}$ NASSER, Kamal HI. - Creative Financial Accounting: Its Nature and Use. Prentice Hall International Limited, 1993.

${ }^{33}$ RUTHERFORD, B.A.- The Interpretation of Cash Flow Reporting and Other Allocation Problem. ASBACUS, june, 1982.

${ }^{34}$ MARTINS, Eliseu. - Op. Cit.

${ }^{35}$ IUDíCIBUS, Sérgio. - Lucro Contábil - Crepúsculo ou Ressurgimento? Caderno de Estudos, São Paulo: FIPECAFI, outubro, 1989.

${ }^{36}$ MAKSY, Mostafa M. - Articulation Problems Between the Balance Sheet and the Funds Statement. The Accounting Review, v.63, n.4, october, 1988.
} 
1. aquisição e/ou alienação de negócio;

2. operações descontinuadas;

3. ajustamentos de conversão de moeda estrangeira; e

4. imposto de renda diferido.

Os resultados verificados sugeriram que as discrepâncias do Tipo I parecem ser muito mais predominantes que as do Tipo II. Na maior parte dos casos, as do Tipo II não aconteceram por valores significativos e daí, a seu ver, poderiam ser toleradas pelos princípios contábeis generalizadamente aceitos devido a suas imaterialidades. Em outros casos, porém, essas discrepâncias foram bastante expressivas. MAKSY entendeu que o fato de não fornecer uma explanação sobre discrepâncias do Tipo i numa cota explicativa poderia levar o usuário a uma posição difícil, ao passo que as do Tipo II, independente de sua magnitude, violariam os princípios contábeis.

A questão levantada pelo autor da tolerância pelos princípios fundamentais de Contabilidade de discrepâncias do Tipo I devido a não materialidade dos valores envolvidos, e de sua violação pelas do Tipo II, materiais ou não, parece arranhar a relevância informativa do relatório.

\section{EVIDÊNCIAS DA RELEVÂNCIA INFORMATIVA DO RELATÓRIO}

Poucas pesquisas têm sido divulgadas sobre a utilidade das informações descritas na DFC, enquanto boa parte daquelas existentes se acha voltadas a seu uso como determinante do preço de mercado das ações. O estudo de EPSTEIN e PAVA ${ }^{37}$ procurou identificar as preferências e necessidades dos usuários e, para isso, enviaram 2.359 questionários a acionistas selecionados aleatoriamente representativos dos 50 estados norte-americanos, tendo sido respondidos 246 deles. As respostas foram analisadas estaticamente e comparadas aos resultados de uma pesquisa semelhante realizada por um dos autores em $1973 .^{38}$. Ou seja, foram confrontadas as respostas dos investidores antes da emissão do SFAS no. 95 (artigo de 1973), e após esse momento (1991).

\footnotetext{
${ }^{37}$ EPSTEIN, M. J. \& PAVA, M. L.- How Useful is the Statement of Cash Flows? Management Accounting, v.70, n.7, july, 1992.

${ }^{38}$ EPSTEIN, M. J - The Usefulness of Annual Reports to Corporate Stockholders. Bureau of Business and Economics Research. California State University, Los Angeles, Cal., fall, 1975.
} 
Quando inquiridos sobre a leitura do relatório, os resultados sinalizaram que a maioria $(51,8 \%)$ dos investidores lia a DFC de uma forma completa. Embora continuassem a ler a Demonstração de Resultado e o Balanço Patrimonial mais do que a DFC, ficou claro que hoje gastam mais tempo nessa última que em 1973 (45,9\%). Notaram que, apesar de que a leitura da DFC tenha aumentado, a da Demonstração de Resultado caiu de maneira substancial - diminui em $11 \%$ durante os 17 anos passados (1973, 71,8\%, versus $1991,60,5 \%$ ). Logo, concluíram os autores que os investidores compreendem cada vez mais a DFC.

No tocante `a questão específica do nível de entendimento do demonstrativo, explicaram que mais de $71 \%$ de todos os investidores não relataram que a Demonstração era difícil de entender. Além disso, enquanto esse relatório foi divulgado para ser levemente mais difícil de entender que o Balanço Patrimonial (fluxos de caixa, 28,5\% e balanço $28,1 \%$ ) e bem mais difícil que a Demonstração de Resultado (demonstração de resultado, 15,7\%), a dificuldade decresceu de modo significativo ao longo das duas décadas passadas. Acham os autores que a DFC é muito mais fácil de interpretar que sua predecessora - a qual adotava o conceito de capital de giro. Assim, concluíram que pouca variação ocorreu para a Demonstração de Resultado, ao passo que houve um dramático declínio na dificuldade para a DFC.

Com respeito à questão sobre qual demonstrativo seria desejável uma maior explicação, verificou-se que mais de $40 \%$ dos respondentes concordaram com referência à DFC. Entenderam os autores que, embora o demonstrativo tenha evoluído, uma considerável maioria ainda encontrava dificuldade em entendê-lo, e acreditavam que uma maior explicação os auxiliaria em decisões de investimento.

Uma outra questão avaliada foi sobre a utilidade dos relatórios financeiros para fins de decisões de investimento. Os resultados apontaram que a maioria dos investidores relatou que a DFC consistia numa fonte útil de informação (50,2\%). Perceberam ainda que, à despeito de haver se posicionado pior que os outros dois relatórios, o número de investidores que a acharam útil elevou-se fortemente entre 1973 e 1990 - em igual período a utilidade da demonstração de resultado decresceu em $7 \%$. Concluíram, pois, que os investidores vinham utilizando mais a DFC e menos a Demonstração de Resultado.

Os autores sugerem que o aumento de interesse e compreensão do demonstrativo foi atribuído aos seguintes fatores: 
1. SFAS no. 95. - as modificações introduzidas por essa Instrução facilitaram a interpretação e difusão do relatório, permitindo comparações entre as empresas numa base compreensível;

2. a consciência do investidor - em especial quanto à importância do caixa para as decisões de investimento;

3. a deterioração na credibilidade do lucro contábil - os investidores aumentaram suas desconfianças sobre o montante do resultado contábil, não mais o visualizando como uma medida suficiente do desempenho da firma.

Como pode ser percebido, o estudo comparou respostas que confrontavam Balanços e Demonstrações de Resultado de ambas as épocas, mas CGL (de 1973) ao Fluxo de Caixa (de 1991), fato que pode provocar conclusões inconsistentes. Parece evidente a maior simplicidade e compreensividade das DFC comparada àquela que divulgava as mudanças no CGL. Desse modo, isso favoreceu ao aumento de leitura da DFC, e até mesmo a menor utilização da Demonstração de Resultado. Assim, as conclusões dos autores podem ser duvidosas.

\section{CONCLUSÃO}

$\tilde{A}$ despeito da tendência observada nos países mais desenvolvidos ${ }^{39} 39$ no tocante `a utilização da DFC, no Brasil as normas societárias em vigor não estimulam a publicação de outros relatórios que adotam conceito de recursos diferente do Capital Circulante Líquido. ADFC, por exemplo, poderia muitas vezes fornecer informações mais relevantes sobre liquidez e solvência, e de mais fácil entendimento, as quais não são mostradas na DOAR tradicional (ao menos de uma maneira tão transparente), como no caso das instituições financeiras. Somente recentemente o Banco Central do Brasil solicitou às empresas do setor a divulgação de demonstrativos com base em caixa.

Em princípio, seria mais coerente que as próprias companhias, ou suas respectivas associações representativas, determinassem qual conceito adotar para atendimento às necessidades informativas de seus usuários.

Por outro lado, deve ficar claro que as informações contidas na Demonstração de Resultado - os lucros - e na DFC- distribuídas entre as três atividades básicas do empreendimento

\footnotetext{
${ }^{39}$ WALLACE, R.S. \& COLLER, P.A.- The "Cash" in Cash Flow Statements: A Multi-Country Comparison. Accounting Horizons, v.5, n.4, december, 1991.
} 
- são diferentes e atendem a propósitos diversos: lucratividade e liquidez, respectivamente. O que se verifica, sim, é uma tendência no sentido do abandono da DOAR usual em prol da DFC. Os fatos parecem sinalizar esse relatório como mais relevante aos usuários em suas avaliações de curto prazo que a DOAR e, dessa forma, a substituição desta última poderia ser adequada.

Com base nos prós e contras discutidos ao longo desse artigo, parece sustentável o argumento de que os usuários da DFC a lêem mais em relação à demonstração das mutações na posição financeira (a nossa DOAR) no contexto norte-americano, sobretudo em função de sua maior compreensividade para decisões financeiras de curto prazo. Essa constatação poderia favorecer a publicação regular do relatório no Brasil, também para as companhias não financeiras. Contudo, existem problemas à medida que possam surgir inconsistência na elaboração e apresentação do demonstrativo, principalmente aquelas que apontam para uma suposta violação aos Princípios Fundamentais de Contabilidade. Ainda assim, poucas evidências conclusivas existem a esse respeito.

\section{RESUMO}

Uma das discussões, ainda presente no cenário contábil nacional, diz respeito à suposta melhor qualidade da informação divulgada pela Demonstração do Fluxo de Caixa em face à DOAR usual. Neste sentido, as principais alegações ressaltam sua relativa simplicidade e facilidade de interpretação no atendimento às necessidades dos usuários; em especial, aqueles externos à entidade. A exposição do confronto entre recebimentos e pagamentos oriundos das três atividades fundamentais do negócio - operações, financiamentos e investimentos - em principio, permitiria um melhor subsídio para as decisões de investimento, haja vista sinalizar de modo mais claro e objetivo a situação de liquidez e solvência da empresa. Todavia, a despeito de, presumivelmente, evitar rateios de custos e, assim, inibir a "maquilagem" dos relatórios financeiros, essa alegação favorável à demonstração não se verifica na prática, uma vez que o relatório pode camuflar atrasos deliberados de pagamentos e antecipações planejadas de recebimento, com o beneficio de um exercício social em detrimento dos outros(s). Em adição, a existência de discrepâncias em alguns de seus itens integrantes, no tocante às variações mostradas no Balanço, parece representar uma desvantagem fundamental, notadamente por "violar" determinados princípios contábeis. Seria conveniente que a provável substituição da DOAR resultasse em debates, sobretudo com a exposição das deficiências inerentes ao novo relatório contábil, que venha a substituí-lo. 


\section{REFERÊNCIAS BIBLIOGRÁFICAS}

BEAVER, W.H. - Alternative Accounting Measures as Predictors of Failure. The Accounting Review, v. 43. n.1, january, 1968.

DRTINA, R. \& LARGAY, J.A. - Pitfalls in Calculating Cash Flow form Operations. The Accounting Review, v.60, n. 2, april 1985.

EPSTEIN, M.J.- The Usefulness of Annual Reports to Corporate Stockholders. Bureau of Business and Economics Research, California State University, Los Angeles, Cal., fall, 1975.

FESS, P.F. - The Working Capital Concept. The Accounting Review, v. 45, n. 2, april, 1966.

GOLUB, S. J. \& HUFFMAN, H.D. - Cash Flow: Why it Should be Stressed in Financial Reporting. Financial Executive, v.52, n. 2, february, 1984.

GUP, B. E. DUGAN, M.T. - The Cash Flow Statement: The Tip of an Iceberg. Business Horizons, v. 31, n.6, november / december, 1988.

HEATH, L.C. - Cash Flow Reporting: Bankers Need a Direct Approach. The Journal of Commercial Bank Lending, february, 1987.

.- Is Working Capital Really Working?. Journal of Accountancy, v. 150, n. 2, august, 1980.

HEATH, L. C. \& ROSENFIELD, T.- Solvency: The Forgotten Hall of Financial Reporting. Journal of Accountancy , v. 146, n. 4, october, 1978.

HENDRISKEN, E.S. \& VON BALDA, M.F. - Accounting Theory. Fifth edition, Homewood, Illions: Irwin, 1993. 
HOPP, J.C. e LEITE, H.P. - O Mito da Liquidez. Revista de Administração de Empresas, São Paulo, FGV, v. 29, n. 4, out / dez, 1989.

IJIRI, Yuji - Recovery Rate and Cash Flow Accounting. Financial Executive, v. 48, n. 3, march, 1980.

IUDíCIBUS, Sérgio - Lucro Contábil - Crepúsculo ou Ressurgimento? Caderno de Estudos, São Paulo: FIPECAFI, outubro de 1989.

KETZ, J.E \& KOCHANEK, R.F. - Cash Flow: Assessing a Company's Real Financial Health, Financial Executive, v. 50, n. 7, july, 1982.

KOCHANEK, R. - Fundos Statement Financial Executive, v. 3, n. 1, january, 1987.

MAHONEY, John J. \& SEVER, Mark V. \& THEIS, John A. - Cash Flow: FASB Opens the Floodgates. Journal of Accountancy, v. 165, n. 5, may, 1988.

MAKSY, Mostafa M. - Articulation Problems Between the Balance Sheet and the Funds Statement. The Accounting Review, v. 63, n. 4, october, 1988.

MARTINS, Eliseu - Contabilidade vs. Fluxo de Caixa. Caderno de Estudos, São Paulo: FIPECAFI, abril, 1990.

MAURIELLO, L. A. - The Working Capital Concept: A Restatement. The Accounting Review, v. 37, n.1, january, 1962.

NASER, Kamal HI. - Creative Financial Accounting: Its Nature and Use. Prentice Hall International Limited, 1993.

RUTHERFORD, B. A. - The Interpretation of Cash Flow Reporting and Other Allocation Problem. ABACUS, june, 1982. 
SHILLINGLAW, G. \& MEYER, P.E. - Accounting: A Management Approach. Eight edition, Homewood, Illions: Irwin, 1986.

Statement of Financial Accounting Standards no. 95 - Statement of Cash Flows. Financial Accounting Series. Financial Accounting Standards Board of the Financial Accounting Foundation, november, 1987.

VATTER, W. H. - The Fund Theory of Accounting and the Implications for Financial Reports. Chicago: University of Chicago Press, 1947.

WALLACE, R. S. \& COLLER, P. - A. The "Cash" in Cash Flow Statement: A MultiCountry Comparison. Accounting Horizons, v. 5, n.4, december, 1991. 